\title{
THE AETIOLOGY OF CONGENITAL ANGULATION OF TUBULAR BONES WITH CONSTRICTION OF THE MEDULLARY CANAL, AND ITS RELATIONSHIP TO CONGENITAL PSEUDARTHROSIS
}

\author{
R. L. M. Newell and F. C. Durbin, Exeter, England
}

\begin{abstract}
It is suggested that there is a group of cases of congenital angulation of tubular bones in which the lesion is a defect of ossification of the primary cartilaginous anlage and in which neurofibromatosis is not implicated.

It appears that in this group the prognosis with regard to the resolution of deformity and the prevention of pseudarthrosis with conservative treatment or relatively simple surgical procedures is better than that in the neurofibromatous type.
\end{abstract}

In 1952 Badgley and his associates described a number of cases of congenital bowing of the tibia and discussed the characteristic clinical and radiological appearances (Badgley, O'Connor and Kudner 1952). The term "congenital kyphoscoliosis of the tibia" was proposed and it was suggested that these cases represented a stage of "congenital" pseudarthrosis of the tibia before fracture. In only two of the twenty cases described was there

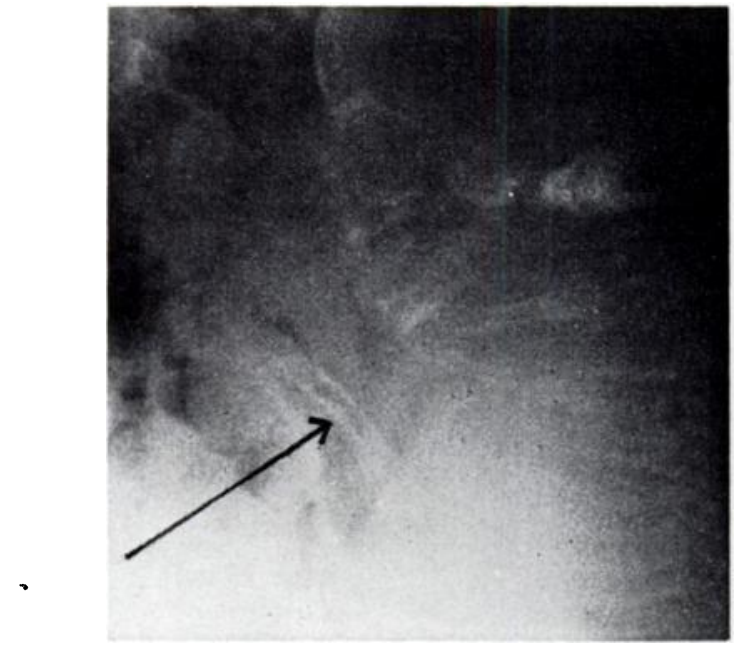

Fig. 1
A transradiant area at the site of angulation was frequently noted, as was the occurrence of associated developmental anomalies in the distal lower limb on the affected side. The work of Bagg (1929) and of Warkany and Nelson (1942) was held to support a very early developmental defect as the cause of the lesion.

Badgley's work has received little attention in the British literature, though the concept of the stage before

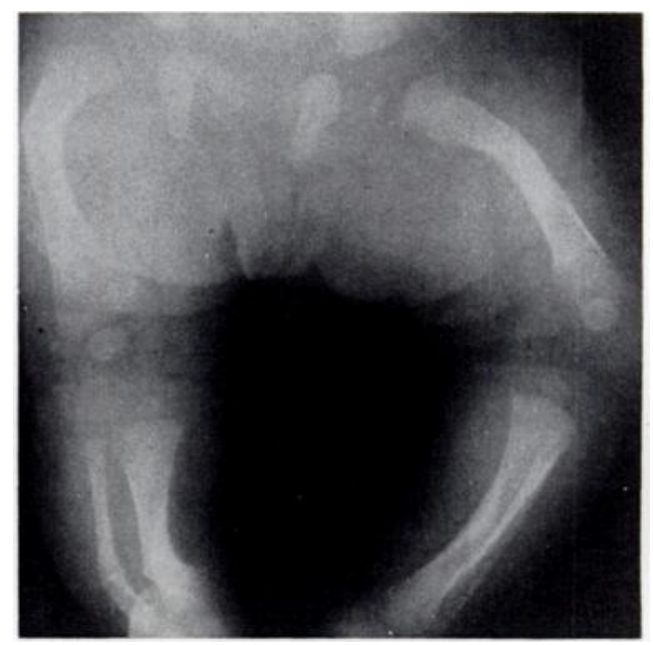

FiG. 2

Case 1. Figure 1-Radiograph of foetus in utero showing narrowed medullary canal of tibia (arrowed). Figure 2-Lower limbs.

definite clinical evidence of neurofibromatosis. Rathgeb, Ramsey and Cowell (1974) recently modified Badgley's classification and defined the appearance of those bowed tibiae in which the risk of development of pseudarthrosis is high.

Badgley and his colleagues discussed in detail the nature and probable embryonic origin of the lesion in the tibia, and defined its characteristics to include the abnormal, narrowed and conical medullary canal, the dense bony mass on the concave side of the bow at the site of angulation, and the tendency to spontaneous correction by normal metaphysial growth. fracture and its management have been discussed by Lloyd-Roberts and Shaw (1969) in cases of neurofibromatosis.

In 1962 Dunn and Aponte described the post-mortem appearances of a child with congenital bowing of both tibiae and the left femur, including radiological and histological findings, and related them to Badgley's work. Unfortunately, inadequate quality of fixation prevented the reproduction of the histological appearances in their article. There was no macroscopic or microscopic evidence of neurofibromatosis in this case.

In the present report we include a further patient 
who showed the radiological features described by Badgley and colleagues in the tibia, together with similar appearances in the femora, and also another patient with similar features in a digital phalanx. Finally, histological evidence is presented from a third patient confirming the its breech position) strongly suggested cortical thickening on the concave aspect of the tibia (Fig. 1). Later radiographs showed the conical medullary canals and increased density of the concave aspects of the affected bones (Figs. 2 to 4). The child was treated conservatively and is now aged thirteen. The upper and lower limbs appear normal except for 2.5

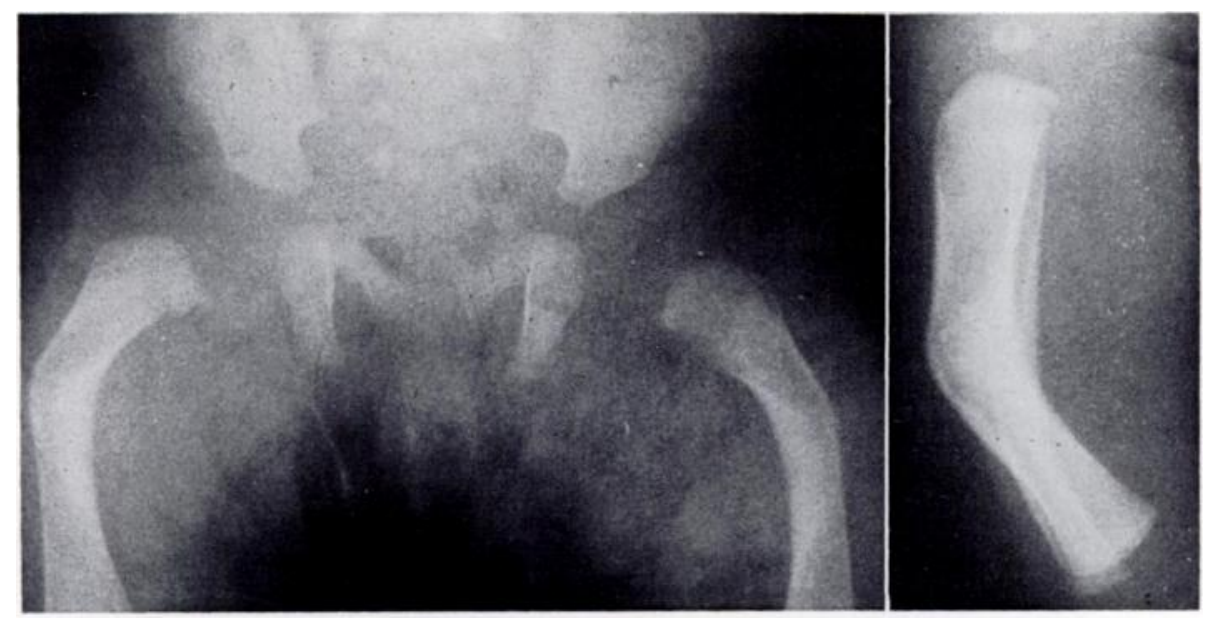

Fig. 3
Fig. 4

Case 1. Figure 3-Appearance of femora at birth. Figure 4-Right tibia.

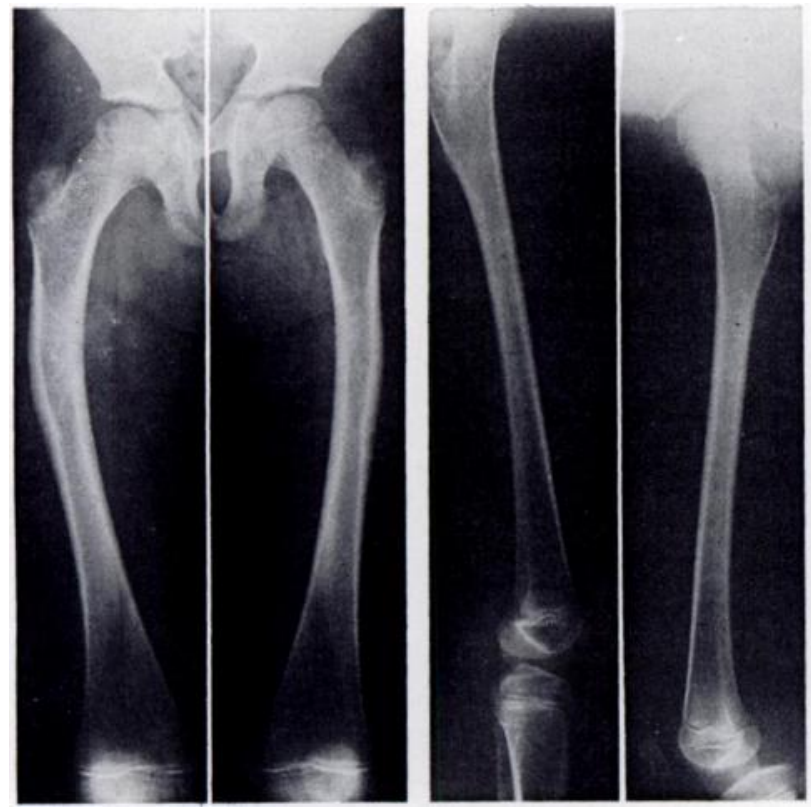

FiG. 5

Case 1-Femora at age of 8 years.

findings of Dunn and Aponte and supporting the aetiological views of Badgley and his associates. In none of these patients has any evidence been found of neurofibromatosis.

\section{CASE REPORTS}

Case 1-A girl was born with bowing of the right tibia and of both femora. A radiograph of the foetus (to demonstrate
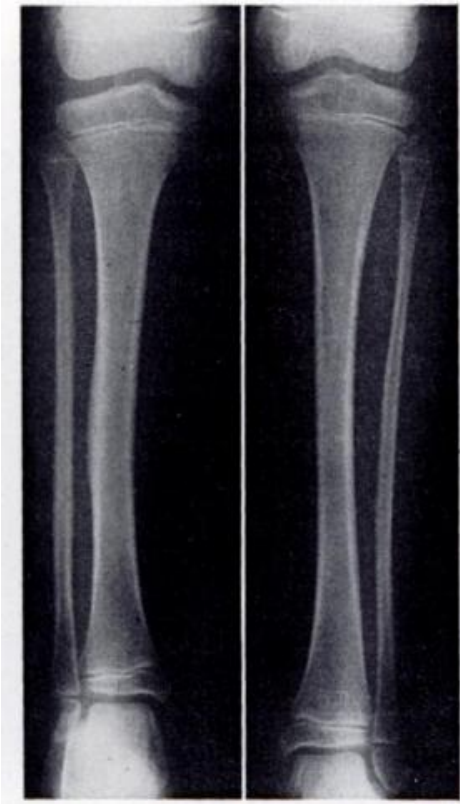

Fig. 6

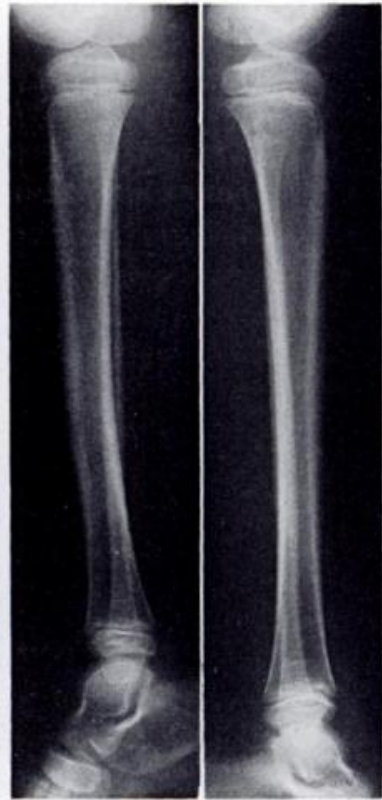

Case 1 -Tibiae at age of 8 years.

centimetres of shortening of the right lower limb. This disparity has not increased for eleven years (Figs. 5 and 6).

Case 2-A child was born with radial deviation of the left index finger. Figure 7 shows the abnormal proximal phalanx with bowing and constriction of the medullary canal.

Case 3-A boy was born with a supernumerary hallux. Radiographs taken at the time showed an abnormal tibia (Fig. 8) but this was not noticed and treatment was directed to the foot. A little bowing of the tibia was noted when the 
child was eighteen months old but the deformity was never very marked. Between the ages of nineteen months and three years the boy suffered three fractures of the tibial shaft at the same site, each produced by minimal violence. There was a

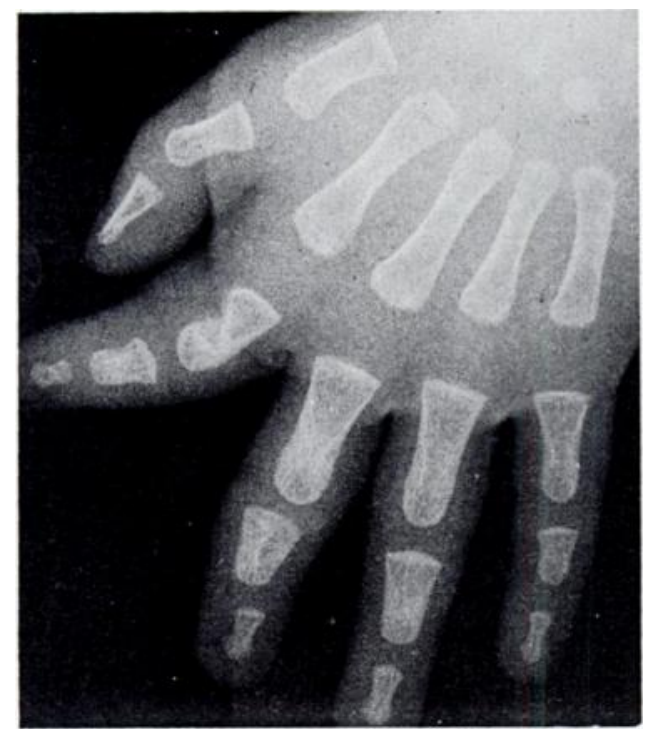

Fig. 7

Case 2-Left hand showing abnormal proximal phalanx of index finger.

persistently abnormal medullary canal with a transradiant cortical area at the site of the medullary constriction and a dense triangular area of bone on the medial side (Fig. 9). In view of the persistently abnormal radiographic features it was decided to carry out an excision biopsy of the transradiant lesion and to open up the abnormally constricted medullary

\section{DISCUSSION}

Most of the previous work on congenital angular deformity of the tibia in children has tended to concentrate on the stage of pseudarthrosis and its management, and has stressed the role of neurofibromatosis in the aetiology of the pseudarthrosis. Lloyd-Roberts and Shaw (1969) emphasised the importance of the stage before fracture but implied that their cases were also of the neurofibromatous type and showed histological evidence of this. Some speculations were made by Aegerter (1950) but not until the work of Badgley and his colleagues in 1952 was a theory suggested which involved the primary cartilaginous anlage as the site of origin of the abnormality. Badgley observed that the site of maximal angulation of the tibia and of the narrowest point of the medullary canal was that of the primary ossification centre for the shaft of the bone. His discussion was confined to tibial bowing, but the site of the abnormalities in other bones in Cases 1 and 2 supports this theory. The histological appearance of cartilage at the site of the lesion was described by Dunn and Aponte in 1962, and this cartilage coincided with the radiographic appearance of cortical transradiancy at the angulation. Duraiswami (1955) produced an identical appearance in the chick tibia by injecting the embryo with thallium nitrate and illustrated the cartilage plate and the radiographically "cystic" areas in this article. The appearance and situation of these lesions conform with the findings in Case 3 and fit with Badgley's theory of an early cartilage anomaly with

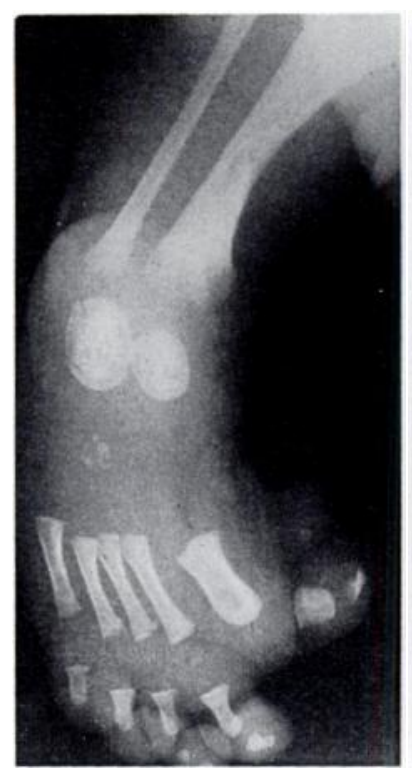

FIG. 8

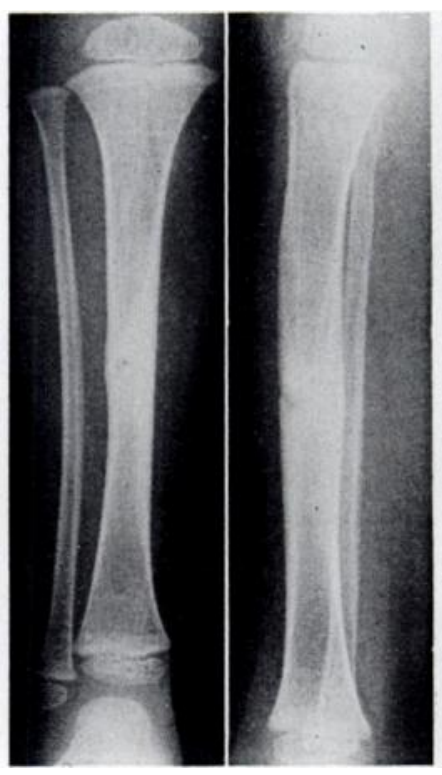

FIG. 9

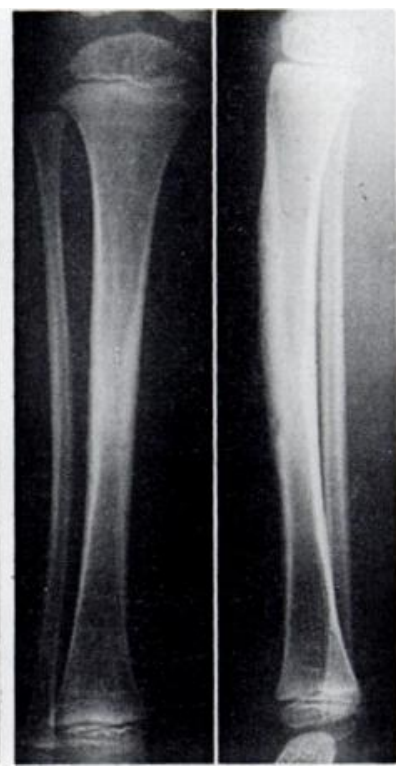

FIG. 10

Case 3. Figure 8-Showing abnormal tibia and supernumerary hallux. Figure 9-Persistent abnormality of tibia with medullary constriction and transradiant area. Figure 10-Tibia one year after excision biopsy and sliding graft.

canal in each direction. The resulting cortical defect was filled with a sliding graft from the proximal tibia. One year after the operation the leg was clinically normal with the radiographic appearances shown in Figure 10. The excised lesion proved to be a plate of cartilage (Fig. 11). No neural tissue was found. failure of ossification. The clinical course in Case 1 confirms Badgley's views on spontaneous correction both in the tibia and the femora. In Case 3 the rapid return of the medullary canal to normal after operation may be associated with the fact that the lesion was excised and 
contrasts with the usual course after operation in neurofibromatous angulation or pseudarthrosis. It appears that there is a group of cases of congenital angular deformity of tubular bones in which there is no evidence of neurofibromatosis and in which the initial angulation is not severe. The prognosis for resolution spontaneously or following relatively minor operation is much better than that of the neurofibromatous type. This group may experimentally in the chick embryo by the use of a number of different teratogenic agents.

A similar lesion may also be present in congenital pseudarthrosis of the clavicle, the aetiology of which remains obscure (Lloyd-Roberts, Apley and Owen 1975). The work of Koch (1960) and of Gibson and Carroll (1970) suggests that the clavicle also ossifies from one primary centre in the middle of the shaft-the site of the

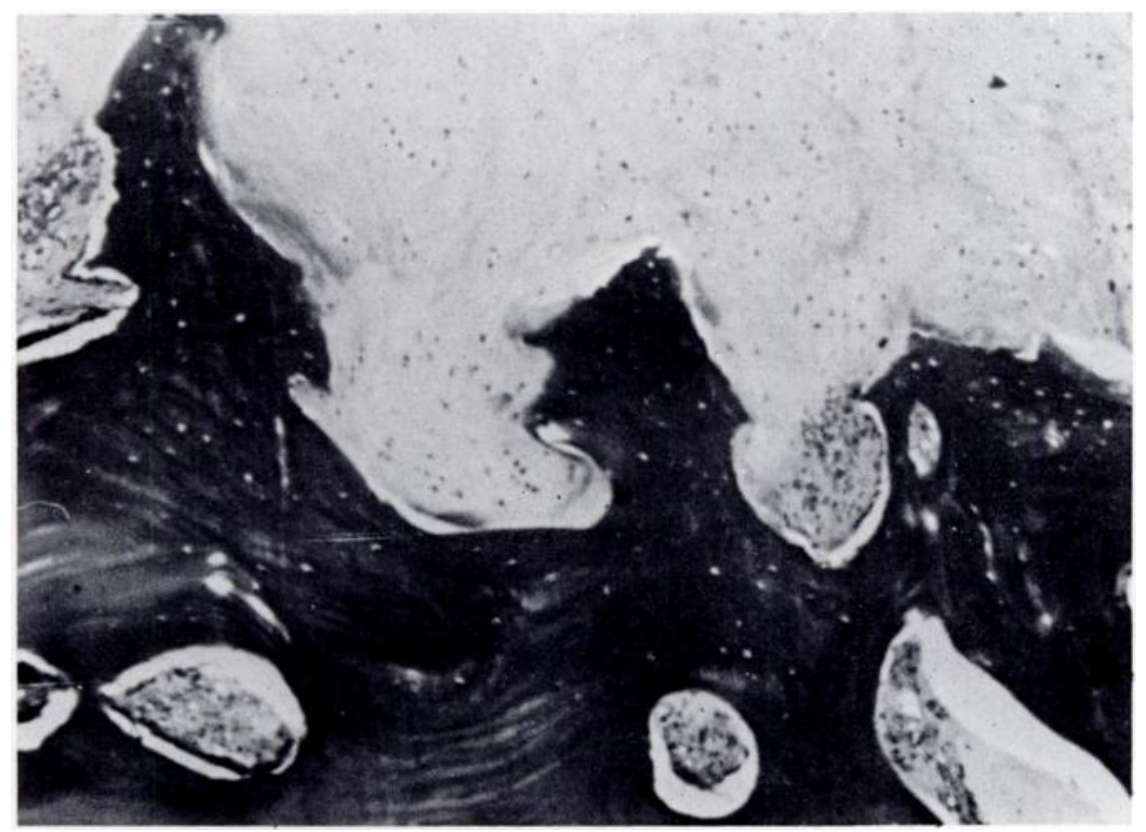

FIG. 11

Case 3-Photomicrograph of tibial lesion.

represent the "Group 2" of Hardinge (1972) though Hardinge himself does not discuss the pathology of his Group 2 cases and only refers briefly to the prognosis with conservative treatment.

It is suggested that in such cases in tubular bones which ossify from a primary centre for the shaft the lesion occurs at a very early stage of development of the cartilaginous anlage. The lesion can be reproduced exactly pseudarthrosis. In the series described by Gibson and Carroll the two cases in which histological material was available showed well formed cartilage covering the bone ends at the site of the lesion. Possibly a similar explanation holds for another lesion of incomplete ossificationthat of the femoral neck in congenital coxa vara, in which Barr (1929) reported finding the inclusion of embryonic cartilage in normal bone.

We wish to thank Dr R. A. Caldwell for his help with the histological examination in Case 3, and Mr P. J. Scott for permission to publish details of Case 2.

\section{REFERENCES}

Aegerter, E. E. (1950) The possible relationship of neurofibromatosis, congenital pseudarthrosis and fibrous dysplasia. Journal of Bone and Joint Surgery, 32-A, 618-626.

Badgley, C. E., O'Connor, S. J., and Kudner, D. F. (1952) Congenital kyphoscoliotic tibia. Journal of Bone and Joint Surgery', 34-A, 349-369.

Bagg, H. J. (1929) Hereditary abnormalities of the limbs, their origin and transmission. II. A morphological study with special reference to the etiology of club-feet, syndactylism, hypodactylism, and congenital amputation in the descendants of x-rayed mice. American Journal of Anatomy, 43, 167-219.

Barr, J. S. (1929) Congenital coxa vara. Archives of Surgery, 18, 1909-1919.

Dunn, A. W., and Aponte, G. E. (1962) Congenital bowing of the tibia and femur. Journal of Bone and Joint Surgery, 44-A, 737-740.

Duraiswami, P. K. (1955) Comparison of congenital defects induced in developing chickens by certain teratogenic agents with those caused by insulin. Journal of Bone and Joint Surgery, 37-A, 277-294.

Gibson, D. A., and Carroll, N. (1970) Congenital pseudarthrosis of the clavicle. Journal of Bone and Joint Surgery, 52-B, 629-643.

Hardinge, K. (1972) Congenital anterior bowing of the tibia. Annals of the Royal College of Surgeons of England, 51, 17-30.

Koch, A. R. (1960) Die Frühentwicklung der Clavicula beim Menschen. Acta Anatomica, 42, 177-212.

Lloyd-Roberts, G. C., Apley, A. G., and Owen, R. (1975) Reflections upon the aetiology of congenital pseudarthrosis of the clavicle. Journal of Bone and Joint Surgery, 57-B, 24-29.

Lloyd-Roberts, G. C., and Shaw, N. E. (1969) The prevention of pseudarthrosis in congenital kyphosis of the tibia. Journal of Bone and Joint Surgeri, 51-B, 100-105.

Rathgeb, J. M., Ramsey, P. L., and Cowell, H. R. (1974) Congenital kyphoscoliosis of the tibia. Clinical Orthopaedics and Related Research, $103,178-190$.

Warkany, J., and Nelson, R. C. (1942) Congenital malformations induced in rats by maternal nutritional deficiency. Journal of Nutrition, 23, 321-333. 